\title{
O CORPO E O TEMPO: A PERCEPÇÃO DOS IDOSOS DE UM GRUPO DE CONVIVÊNCIA
}

\author{
Giulyanne Maria Lima da Silva \\ Universidade de Pernambuco, Recife, Pernambuco, Brasil \\ Iraquitan de Oliveira Caminha \\ Universidade Federal da Paraíba, João Pessoa, Paraíba, Brasil \\ Isabelle Sena Gomes \\ Universidade Federal da Paraíba, João Pessoa, Paraíba, Brasil
}

\begin{abstract}
Resumo
O crescimento do número de idosos na sociedade brasileira tem estimulado a busca dos pesquisadores em compreender este complexo processo na vida do ser humano. Para o indivíduo idoso, esta fase da vida é marcada por diversas modificações nos aspectos biopsicossociais, que são percebidas conforme o contexto sociocultural no qual está inserido. Nessa perspectiva, este estudo levanta o seguinte questionamento: Quais os componentes sociais da percepção corporal dos idosos participantes de um grupo de convivência? A partir dessa questão, buscou-se analisar a percepção corporal dos idosos participantes de um grupo de convivência e seus componentes sociais. Tratou-se de um estudo descritivo qualitativo de natureza fenomenológica cujos sujeitos foram 6 idosos de ambos os sexos de 60 a 75 anos participantes do grupo de convivência Idosos Ativo da cidade de Bayeux. O instrumento consistiu num roteiro de entrevista e os depoimentos foram analisados por meio da técnica de análise do conteúdo das transcrições nas quais se destacou os componentes sociais expressos na fala dos sujeitos. Concluiu-se que a sociedade atua de forma significante nas percepções dos idosos sobre o envelhecimento e sua auto-imagem. Contudo sugerimos a realização de novos estudos com idosos em diferentes contextos, além dos participantes de grupos de convivência, com o intuito de aprofundar os conhecimentos acerca da influência social sobre o idoso.
\end{abstract}

Palavras-chave: Envelhecimento. Autoimagem. Grupo social.

\section{Introdução}

$\mathrm{O}$ envelhecimento populacional é um tema que ganhou espaço nas discussões, principalmente a partir do período pós-guerra. $\mathrm{O}$ aumento da expectativa de vida, a redução do número de nascimentos e a evolução da ciência na direção do prolongamento da vida - e não mais da "não-morte" - colaboraram para que o Brasil passasse de um perfil de morbimortalidade característico de países jovens, para um 
quadro de resiliência típico de populações com idade mais avançada (VERAS, 2011).

Este fato impulsionou a realização de estudos provindos de diversas áreas no intuito de compreender melhor as singularidades desta fase da vida, determinada pelo contexto histórico, social e cultural. Vitola e Argimon (2003) advertem que os conceitos de idade não são fixos e variam entre gerações e culturas. Assim, a relativização das fronteiras etárias - devido à variação no contexto sociocultural - altera os limites da percepção do que é ser velho e do que é ser jovem (MORAES, 2011).

A interpretação social da velhice é geralmente cercada por aspectos negativos. Segundo autores como Ibias (2003) e Mediondo e Bulla (2003), esta fase da vida é caracterizada pelas pessoas como um inevitável, desfavorável, decadente e deteriorante processo de difícil controle, marcado por muitas perdas sucessivas. Porém, os mesmos apontam a importância de relevar estes danos por meio dos aspectos positivos e potencialidades desta fase da vida, como a experiência acumulada, o tempo livre disponível e a liberdade de fazer as próprias escolhas. Concordando com essa definição do envelhecimento, Mazo, Lopes e Benedetti (2009) acrescentam a existência de conotações negativas atribuídas a esta fase da vida que agem no imaginário popular produzindo mitos relacionados à busca da possibilidade da imortalidade e juventude.

Ainda sobre o envelhecimento humano e sua complexidade, observa-se que após os 60 anos as modificações nos aspectos biopsicossociais alteram significativamente o cotidiano e a auto percepção do indivíduo. Nahas (2010, p.191) define esse processo como "gradual, universal e irreversível, que acelera na maturidade e que provoca uma perda funcional progressiva no organismo." Para Cardec (2011) é somente aos 80 anos que tem início a "verdadeira velhice", pois, com a gama de possibilidades proporcionada pela ciência e a expectativa de vida podendo chegar aos 100 anos, não flexibilizar o conceito de velhice é superestimar a idade cronológica.

Ainda sobre o envelhecer e suas dimensões - mais especificamente no aspecto psicológico, Rauchbach (2001, p.16) aponta que na "velhice, o equilíbrio psicológico se torna mais difícil, pois a longa história da vida acentua as diferenças individuais". A mesma autora cita que a harmonia do idoso com seu corpo diminui e altera valores e atitudes do individuo. Entretanto, as práticas corporais podem ser aliadas 
na liberação de tensões e aquisição de novos valores capazes de melhorar a auto-estima e melhor percepção de sua imagem corporal.

Diante disto, concluímos que o envelhecimento corporal não é vivido em uma única perspectiva, mas por meio do "corpo orgânico, da aparência e da energia, que exprimem respectivamente preocupações em matéria de saúde, beleza e forma" (CARDEC, 2011, p. 25). Cabe ressaltar que segundo a OMS, saúde envolve ainda: bem-estar físico, mental e social, fazendo do processo de envelhecer algo mais complexo e rico de subjetividades.

Acerca das subjetividades que perpassam o corpo, Le Breton (2007) propõe que este é moldado no contexto sócio-cultural e representa a presença do ser no mundo. Mais especificamente em relação aos idosos, esta imagem corporal apresenta-se repleta de experiências adquiridas ao longo da vida e marcadas pela cultura, sociedade e grupos nos quais o indivíduo encontra-se inserido.

A chamada "terceira idade" tem buscado com frequência os grupos voltados para idosos por serem espaços de convivência e promoção/manutenção da "velhice ativa", na crença da possibilidade de viver melhor "depois dos sessenta" (MORAES, 2011). Nessa perspectiva, o estilo de vida adotado é relevante para a (res)significação da sua auto imagem. Portanto, a participação em grupos de convivência e práticas de exercícios regulares serão elementos influenciadores da percepção da imagem corporal.

Num estudo realizado por Matsuo et al (2007) observou-se que idosas participantes de programas de Atividades Físicas apresentavam uma imagem corporal positiva e as não praticantes concebiam seu corpo de forma negativa. Entretanto, estudos realizados por Alencar (2010) e Siqueira (2008) na região Nordeste com o intuito de conhecer o nível de atividade física desta população apontam baixos índices de atividade física entre idosos. Acrescentando a este dado, Tribess, Virtuoso-Junior e Petroski (2009) afirmam a existência de uma relação entre a condição insuficiente de atividade física com a insatisfação corporal e a obesidade após analisar os fatores associados à inatividade física em mulheres idosas de baixa renda.

Atualmente, mostra-se evidente a importância e os benefícios das relações sociais e dos grupos de convivência após os 60 anos. Dentre as perdas típicas dessa fase, encontra-se a dos laços sociais e familiares devido ao afastamento do trabalho (aposentadoria), ao preconceito e às mortes dos amigos e companheiros. Essa mudança têm diversos 
efeitos psíquicos e até mesmo físicos, dependendo da intensidade ou da continuidade com que ocorrem. De acordo com Mediondo e Bulla (2003, p. 278), a participação em grupos de convivência acarreta em novas situações e "os relacionamentos novos que surgem nos grupos permitem ao idoso ter mais segurança de si mesmo, de suas atitudes, de seus posicionamentos, e aumenta a auto-estima".

O corpo e a importância dos aspectos sociais são apontados por Le Breton (2007, p. 32) ao afirmar que "o corpo não existe em estado natural, sempre está compreendido na trama social de sentidos [...]", mesmo nos momentos de individualidade por meio de gestos, dores, entre outras, a sociedade se faz presente e influencia o individuo. Nessa perspectiva, pode-se recorre a Shilder (1980) para apontar que a construção da imagem corporal se dá por meio das dimensões fisiológicas, psicológicas e sociológicas do indivíduo. Logo, a percepção do corpo idoso é influenciada não só pela sua auto-imagem, mas também pela forma como o meio social em que se encontra a concebe.

Assim, o estilo de vida, o contexto social e a participação em grupos de convivência são elementos relevantes na relação entre o indivíduo e seu corpo. Nesta perspectiva, busca-se responder o seguinte questionamento: Quais os componentes sociais da percepção corporal dos idosos participantes de um grupo de convivência? Diante desse questionamento busca-se analisar a percepção corporal dos idosos participantes de um grupo de convivência e seus componentes sociais. Mais especificamente, esse estudo possui como objetivo identificar os componentes sociais que compõem o conceito de corpo do idoso, a concepção do idoso sobre seu próprio corpo e ao longo de sua vida e analisar a relação entre os componentes apontados e o contexto sociocultural.

Nos últimos 20 anos, os debates sobre modelos de assistência à saúde, inclusive para idosos, levaram os gestores a considerar que as estratégias preventivas são ineficientes. Isto por que muitas vezes a multidisciplinaridade é pensada de forma fragmentada, separando aspectos físicos, mentais e sociais. O resultado disto é o alto custo com as práticas curativas e doenças crônicas, resultantes da baixa possibilidade de prognóstico positivo, levando ao Estado um gasto que poderia ser amenizado com a aplicação de estratégias na Atenção básica à saúde. Dessa forma, evitando o diagnóstico em situação de doença avançada - permitido a partir de internações e quadros patológicos graves. Portanto, entender a percepção do idoso sem dissociar o pro- 
cesso mutável de envelhecimento do seu contexto sociocultural, é fomentar a elaboração de modelos mais sólidos para o cuidado com os idosos (VERAS, 2011).

Nesse contexto, esse estudo justifica-se pelo fato de que os indivíduos idosos vivenciam mudanças biopsicossociais que interferem na forma como percebem seu corpo e consequentemente sua vida. Logo, uma compreensão multidisciplinar da percepção do idoso poderá colaborar no direcionamento dos profissionais de saúde e gerontologia para a construção de estratégias mais eficazes, proporcionando melhores condições de vida para esta parcela crescente da população.

\section{Percurso metodológico}

Esse estudo caracteriza-se como descritivo qualitativo de natureza fenomenológica orientada pela perspectiva da escuta interpretativa do sentido dado ao corpo do idoso. Busca-se compreender a percepção que idosos têm de seu corpo, considerando sua própria perspectiva.

Os sujeitos deste estudo foram idosos, de ambos os sexos. No Brasil, segundo a Lei $\mathrm{n}^{\mathrm{o}} 10.741$ de Outubro de 2003 do Estatuto do Idoso, considera-se idoso o indivíduo com 60 anos ou mais (BRASIL, 2003). $\mathrm{O}$ instrumento consistiu numa entrevista semi-estruturada elaborada para este estudo com questões relacionadas à forma como os idosos percebem o corpo na sua perspectiva e das pessoas com quem convivem. Com a finalidade de registro das falas, utilizou-se um gravador de áudio digital da marca Sony.

O cenário deste estudo foi a cidade de Bayeux mais precisamente o Grupo de Idosos - Idoso ativo- localizado no Ginásio de Esporte Jaime Caetano. O grupo participa no período matutino, nas segundas e quartas, de atividades físicas regulares, palestras sobre saúde e passeios sendo composto por 60 idosos residentes no município.

Inicialmente, esse estudo foi submetido ao Comitê de ética em pesquisas do Centro de Ciências da Saúde pertencente à Universidade Federal da Paraíba. E mediante sua aprovação sob o número 0070/12, o procedimento de coletas consistiu no contato inicial com os responsáveis pelo grupo, explanação sobre os objetivos do estudo e solicitação de permissão para realização de estudo no local. Uma vez permitido no dia acordado previamente foi explicação aos idosos sobre o objetivo do estudo e realização do piloto. Uma vez esclarecidos os sujeitos foram comunicados do sigilo de sua identidade e recebe- 
ram o Termo de Consentimento Livre e Esclarecido para assinatura mediante concordância de sua participação no estudo. E por fim, a aplicação do roteiro de entrevista com registro da narrativa foi feito por meio do gravador de áudio.

As falas desse estudo foram analisadas por meio da técnica de análise do conteúdo da transcrição das entrevistas. Esta constitui num conjunto de técnicas de análise das comunicações, que visa obter, através de procedimentos sistemáticos e objetivos, a descrição interpretativa do conteúdo das mensagens (GOMES; LIMA; SILVA, 2004). As categorias de análise foram: conceito de corpo na opinião do idoso e percepção do idoso em relação ao seu próprio corpo.

\section{Resultados e discussão}

Os sujeitos deste estudo consistiram em 6 idosos com idade entre 60 a 75 anos, de ambos os sexos, sendo dois homens e quatro mulheres que participam regularmente do grupo Idosos ativos na cidade de Bayeux. Observa-se, inicialmente, a superioridade de indivíduos do sexo feminino, realidade apresentada na população brasileira onde esta discrepância apresenta-se acentuada. Souza e Júnior (2007) afirmam que a população idosa feminina representa $60 \%$ no Brasil, sendo compostas por viúvas, solteiras ou separadas, correspondendo a mais da metade das aposentadorias e pensões da previdência social, na zona rural, nas regiões Sul e Nordeste do país. Segundo o PNAD - Pesquisa Nacional por Amostra de Domicílios, realizada em 2009, as mulheres constituem a maioria, representando 55,8\% deste grupo (IBGE, 2010).

A predominância do sexo feminino em grupos de convivência pode ser explicada, Segundo Moraes (2011), por dois motivos: (1) O fato de que a maioria das atividades é direcionada para "elas" - atividades de destreza manual e habilidades tidas como características das mulheres educadas entre 1940-1950; (2) As mulheres que frequentam estes grupos são provindas de estratos urbanos inferiores ou intermediários "(sem nível superior), que exerceram em alguma parte da vida atividades remuneradas de baixa qualificação, como manuais, trabalhos de escritório e no comércio" (MORAES, 2011, p. 438).

A análise das narrativas consistiu num primeiro momento no processo de objetivação das falas transcritas e posteriormente sistematização dos elementos sintetizadores das falas pelos pesquisadores. A partir daí traçou-se os diagramas base para discussão. 
O primeiro questionamento buscou conhecer qual a concepção de corpo dos idosos entrevistados. E a partir deste questionamento obtivemos os componentes: "conjunto de órgãos", "físico", "cuidado", "normalidade", "perfeição" e "vida", relacionados à forma como os idosos compreendem o corpo num contexto geral. Estes se encontram apresentados no diagrama 1, abaixo:

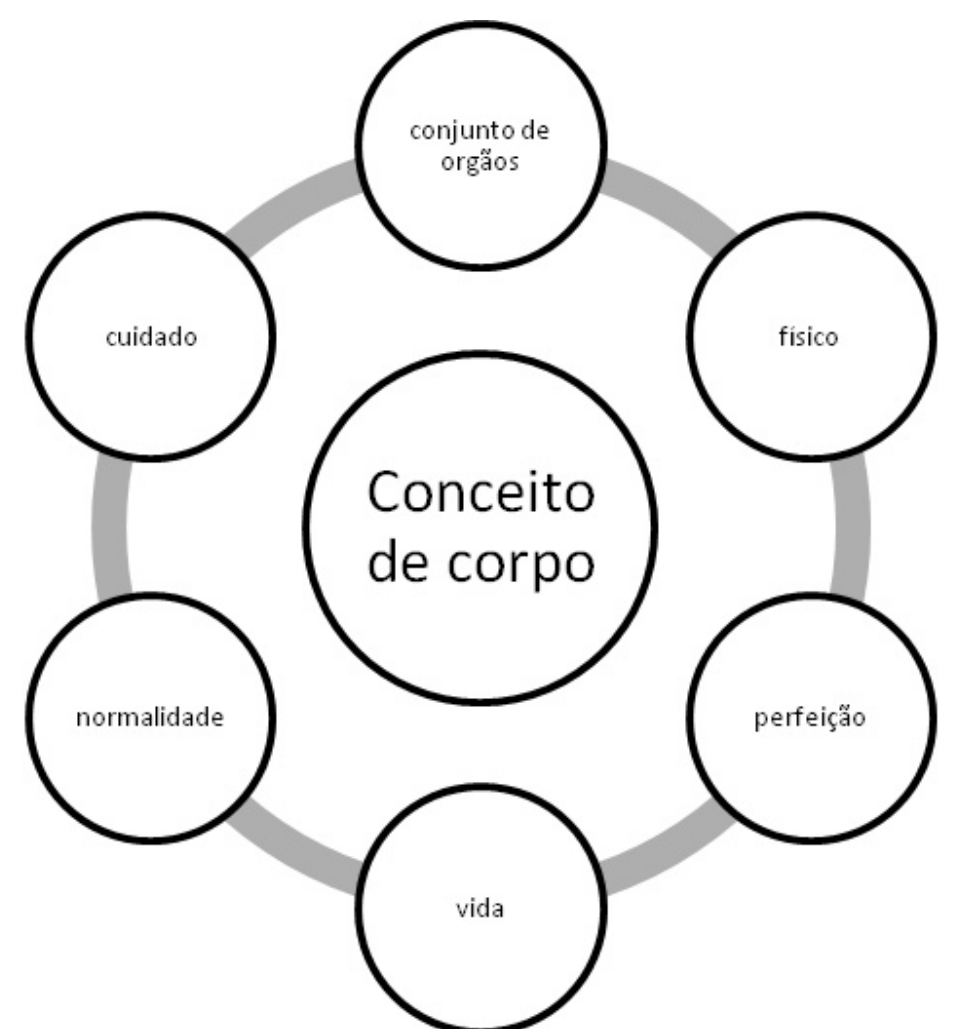

Diagrama 1: Componentes apresentados pelos idosos para conceituar corpo Fonte: Narrativas do estudo

Destaca-se no diagrama acima a presença dos componentes sociais "perfeição" e "normalidade". Esta escolha justifica-se diante do modelo de corpo ideal da sociedade ocidental onde o belo e jovem predominam, o fato de comparar o corpo com a perfeição e a normalidade demonstra a tradução do pensamento social no qual todos devem buscar um padrão comum.

Um dos sujeitos do estudo quando questionado sobre o conceito de corpo respondeu "Meu corpo ele é assim, até que tá bom né, normal né.". Questiona-se o que é ser normal? Trata-se de ser igual a todos independente de idade cronológica ou história de vida? Ou de ser igual aos jovens e belos, ideal da sociedade brasileira? Ferreira, Baumel e 
Gomes (2008) denunciam a preocupação pela aparência ideal, pela insatisfação e pela distorção (geralmente para o lado negativo) da imagem corporal independente de gênero, pois os indivíduos encontram-se cada vez mais obstinados a possuírem o corpo que atenda aos protótipos do ideal imposto pela sociedade.

Porque, nesta "sociedade do espetáculo" que insta a conquistar a qualquer custo a visibilidade e a celebridade midiática para poder 'ser alguém', a velhice é um direito negado [...] um estado corporal que deve ser combatido (SIBILA, 2012, p. 145).

Com base na reflexão anterior, pergunta-se o que é ser perfeito para o idoso diante da seguinte fala: "O corpo é a vida da gente né, Mas o corpo da gente não é perfeito. Perfeito mesmo é Deus!” Esta afirmação pode ser justificada pelo fato de que quando relacionado à satisfação corporal das pessoas mais velhas em relação aos individuos mais jovens, Dantas et al. (2005) afirmam que estes parecem sofrer menos influência do padrão corporal possuindo um desejo menor de ter um "corpo-sarado". Além da menor insatifação corporal em relação aos mais jovens, o autor aponta que os idosos são menos exigentes quanto à sua aparência concordando com Damasceno et al. (2006). Logo, este sujeito apresenta as características apontadas por este autor.

Segundo Mucida (2006), a percepção do sujeito sobre o envelhecimento constitui-se também pela visão do outro sobre a velhice e isso reflete na percepção dos indivíduos e nos parâmetros de sinalização do envelhecimento, apresentado sempre em alguém, mas nunca em si mesmo. Com base nessa afirmação, buscou-se num segundo momento questionar os indivíduos sobre o que significava para eles o seu próprio corpo num intuito de remeter o indivíduo a si. Os componentes apresentados, sentimentos positivos, condição de existência, satisfação e diferença de antigamente, conforme pode ser observado no diagrama 2 abaixo. Novamente os componentes sociais emergiram sendo os selecionados: "satisfação" e "diferente de antigamente". 


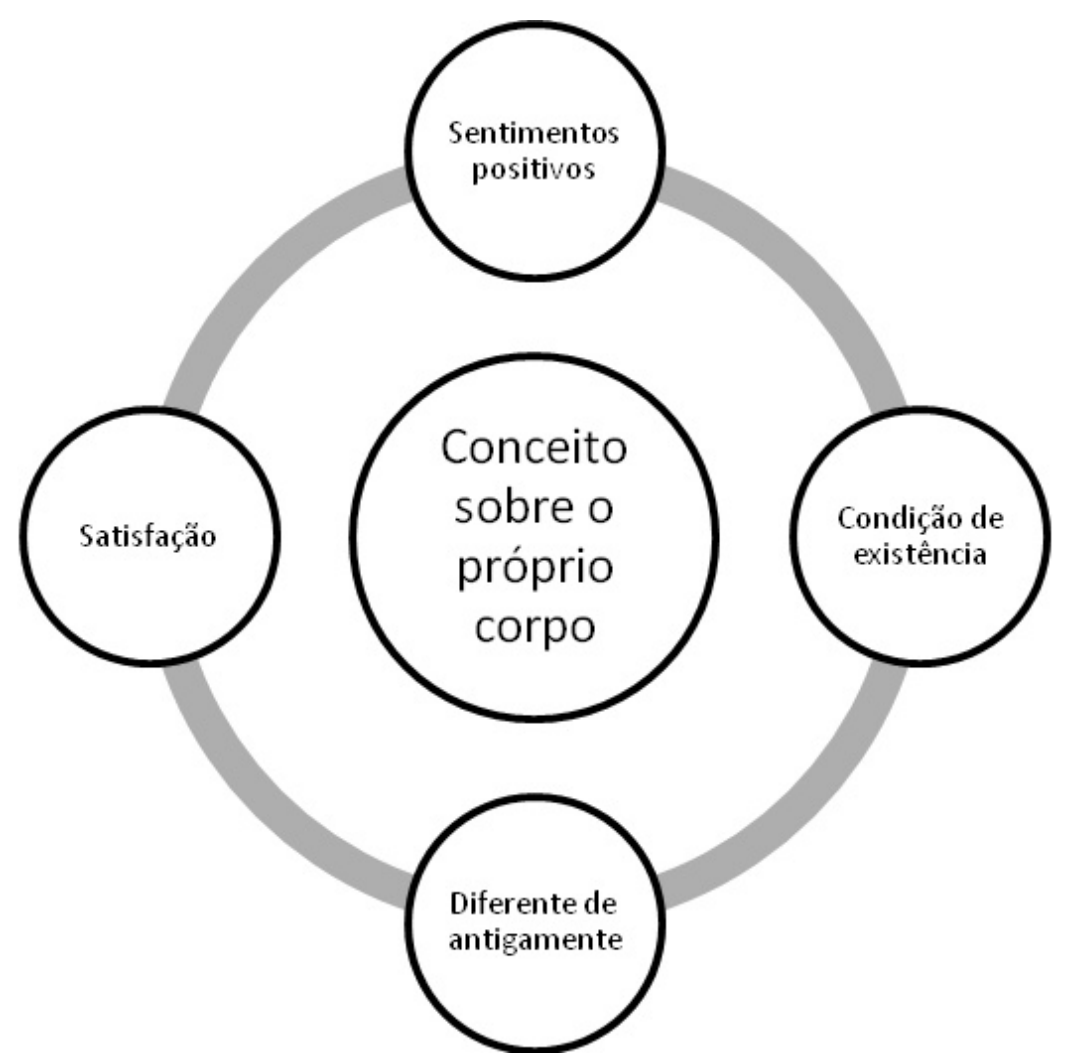

Diagrama 2: Componentes apresentados pelos idosos para conceituar o próprio corpo.

Fonte: Dados do estudo

Atualmente, diante do contexto sócio cultural, a maioria dos estudos sobre o tema vem apontando uma maior incidência de insatisfação em relação ao seu próprio corpo por parte dos idosos. Num estudo de revisão de literatura realizado a partir de 30 textos publicados no periodo entre 1997 e 2008 por Fernandes (2009), constatou que, seguindo modelos culturais, determinantes de relações sociais de gênero e geração, as mulheres idosas vivenciam de modo negativo seu corpo envelhecido.

Contudo, observa-se também a adoção de um novo estilo de vida e a propagação de grupos de convivência e programas de atividades físicas direcionadas para esta crescente parcela populacional. Pode-se apontar a relação positiva entre a realização de práticas corporais e participação em um grupo de convivência como elementos contribuintes para esta satisfação com a imagem corporal. Em estudos (VAZ; NODIN, 2005; MATSUO et al, 2007) constatou-se a influência da participação do idoso em programas que promovem práticas cor- 
porais como determinante na percepção da imagem concebido pelo idoso sobre seu próprio corpo.

A satisfação com o próprio corpo pode ser encontrada nas narrativas construídas a partir do que significa para o idoso o seu próprio corpo. Como exemplo podemos citar: "O que eu tenho é como eu me sinto bem."; "E eu sou feliz com meu corpo."; "Sem ele eu não executaria tantas coisas que eu hoje em dia ainda faço e fazia desde novo até agora.".

Damasceno et al. (2006) concordan com Shilder (1980) e Le Breton (2007) que a imagem corporal é construída com base em fatores socioculturais destaca que diferem no decorrer das fases da vida. Dentre estes fatores, o autor aponta desde a maturação, aumento da massa e alterações na forma corporal como elementos de influência da percepção corporal em diferentes faixas etárias. Assim, diante da propagação do padrão social de corpo ideal como sendo o corpo jovem, enfatiza-se a presença do componente "diferente de antigamente" na fala do idoso que segue: "Não é como era antigamente. Meu corpo agora tá com muita diferença, né?".

Num terceiro momento solicitou-se traçar uma linha do tempo a fim de revelar os componentes relativos às modificações no corpo ao longo da vida (infância, adolescência, juventude e idade adulta) na percepção dos idosos e como estes se sentem em relação às mesmas. E os componentes apresentados foram: "desgaste", "satisfação", "estética", "juventude", "conformismo" e "mudanças na aparência" conforme ilustrado no Diagrama 3. 


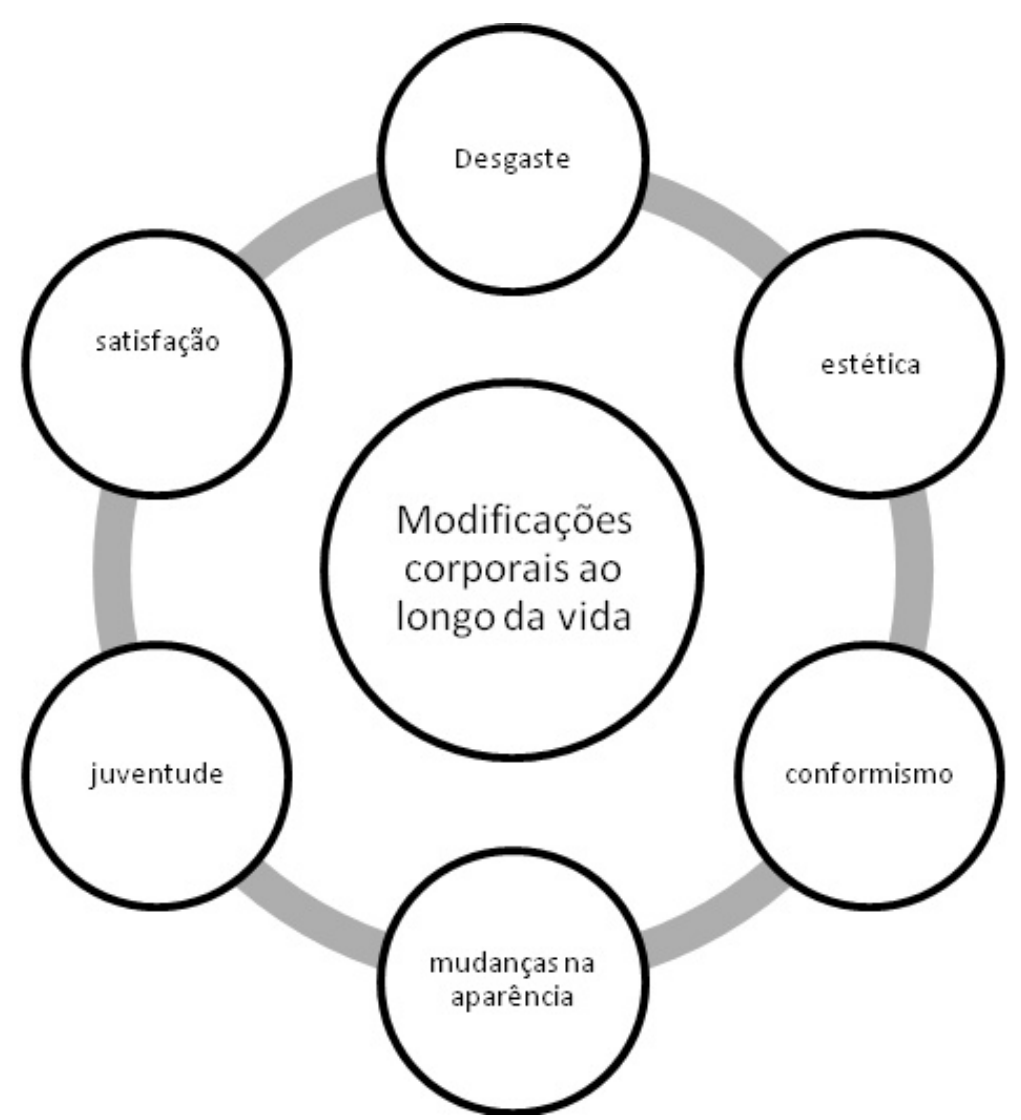

Diagrama 3: Modificações corporais na percepção dos idosos ao longo da vida Fonte: Dados do estudo

Neste diagrama surge novamente o componente social "satisfação" e diante das discussões anteriores podemos criar um único eixo e associar-la à "estética" e "juventude". Trata-se de elementos que reproduzem o pensamento social em relação à imagem corporal ideal. "No cenário público os corpos devem alcançar o ideal almejado, vencendo todos os obstáculos, todas as formas de imperfeição, sobretudo, as marcas da velhice" (SANTAELLA, 2008, p. 128).

Nas narrativas dos idosos observa-se esta relação entre o corpo atual e a comparação, sobretudo, com a juventude e seus aspectos estéticos, conforme observa-se a seguir: "Quando é jovem não tem essas coisas né? Parece mais uma boneca de louça, né. E hoje é diferente. Agora com 72 anos, já tem muita coisa mole, que cai mesmo com o tempo que eu to aqui. E fico sempre me cuidando, sabe. Mas é o que tenho, o corpo."

A satisfação com o corpo possuído não exclui a comparação, sobretudo com o corpo jovem. "[...] numa cultura calcada no imperati- 
vo do "novo" em todos os níveis - vendendo-o sob diferentes formas -, a velhice surge fazendo furo ao ideal de perfeição trazido pela juventude". (MUCIDA, 2006, p.112) Diante disso, das falas dos sujeitos idosos entrevistados e apresentação dos componentes sociais observase a complexidade da percepção corporal do indivíduo, sua estreita relação com a sociedade e seus ideais.

\title{
Considerações finais
}

A composição da imagem corporal e percepção do corpo pelos indivíduos, independente da faixa etária, constitui-se com base na sociedade em que este se encontra. Logo, numa sociedade onde o ideal corporal predominante é caracterizado pela jovialidade, o idoso e as conseqüências do processo de envelhecimento são vistas de forma negativa, interferindo assim na forma como a percepção do corpo será constituída nessa fase da vida.

Diante disso, nesse estudo constatou-se a presença dos componentes sociais: "perfeição", "normalidade", "satisfação", "diferente de antigamente" "estética" e "juventude". Observou-se com base na literatura e nas falas obtidas por meio deste estudo a presença destes elementos socioculturais na percepção corporal dos idosos. Além disso, destaca-se no grupo analisado a participação em atividades sociais e de práticas corporais que contribuem positivamente para a satisfação do idoso com o corpo.

Nessa perspectiva este estudo aponta para novos questionamentos a serem realizados em relação à temática sobre o corpo idoso e a sociedade brasileira. Mais especificamente sugerimos a realização de novos estudos capazes de conhecer melhor a auto imagem dos idosos em diferentes contextos além dos grupos de convivência, considerando a complexidade do processo de envelhecimento. Pois, diante do crescimento populacional necessita-se compreender o universo gerontológico obtendo assim subsídios para intervenções capazes de proporcionar uma maior qualidade de vida e a satisfação com a imagem corporal.

\section{THE BODY AND THE TIME: THE PERCEPTION OF ELDERLY COM- MUNITY GROUP}

\begin{abstract}
The growing number of elderly people in Brazilian society has stimulated the search for researchers in understanding this complex process in human life. For the el-
\end{abstract}


derly, this stage of life is marked by several changes in the biopsychosocial aspects, which are perceived as the sociocultural context in which it is inserted. In this perspective, this study raises the question: What are the social components body perception of elderly participants in a community group? From this question, we attempted to analyze the body perception of the elderly participants in a community group and social components. This was a descriptive qualitative phenomenological whose subjects were 6 elderly of both sexes 60 to 75 years participating in the community group Idoso Ativo in the city of Bayeux. The instrument consisted of a structured interview and the statements were analyzed using the technique of content analysis of the transcripts in which he emphasized the social components of the subjects expressed in speech. It was concluded that the society is active significantly in perceptions of the elderly on aging and self-image. However suggest new studies with elderly in different contexts, and participants in community groups, with the aim of deepening the knowledge about the social influence on the elderly.

Keywords: Aging. Self Concept, Social Group.

\section{EL NÚMERO CRECIENTE DE CUERPO IDOSO Y EL TEMPO: LA PER- CEPCIÓN DE UN GRUPO DE CONVIVENCIA PARA PERSONAS MAYO- RES}

\section{Resumen}

El creciente número de ancianos en la sociedad brasileña ha estimulado la búsqueda de los investigadores en la comprensión de este complejo proceso de la vida humana. Para las personas de edad avanzada, esta etapa de la vida está marcada por varios cambios en los aspectos biopsicosociales, que se perciben como el contexto sociocultural en el que se inserta. En esta perspectiva, este estudio plantea la pregunta: ¿Cuáles son los componentes sociales de la conciencia corporal de los participantes de edad avanzada en un grupo de apoyo? A partir de esta pregunta, hemos tratado de analizar la percepción física de los participantes de edad avanzada en un grupo de apoyo y componentes sociales? Este estudio se trata de un estudio fenomenológico descriptivo cualitativo cuyos sujetos fueron 6 pacientes de ambos sexos, 60 a 75 años, que participan en el grupo de convivência "Idosos ativos da cidade de Bayeux". El instrumento consistió en una entrevista estructurada, y las entrevistas fueron analizadas mediante la técnica de análisis de contenido de las transcripciones, en las que hemos destacado los componentes sociales de los sujetos expresados en las narrativas. Se concluyó que la sociedad opera de manera significativa en las percepciones de las personas mayores sobre el envejecimiento y la propia imagen. Sin embargo nosotros sugierimos nuevos estudios con personas mayores en contextos diferentes, también los participantes en los grupos de convivencia, con el fin de profundizar el conocimiento sobre la influencia social de las personas mayores.

Palabras clave: Envejecimiento. Autoimagen. Grupo Social. 


\section{Referências}

ALENCAR, N. A. et al. Níveis de atividade física em idosas. Estudos interdisciplinares do envelhecimento. Porto Alegre, v. 15, n. 1, p. 87-97, 2010. Disponível em: <http://seer.ufrgs.br/RevEnvelhecer/article/view/8330/10923>. Acesso em 30 maio 2011.

BRASIL. Lei $n^{\circ} 10.741$, de 10 de outubro de 2003. Lex: Estatuto do Idoso, Brasília, DF, 2003.

CARDEC, V. Sexagenários e octogenários diante do envelhecimento do corpo. In: GOLDENBERG, M. (Org). Corpo, envelhecimento e felicidade. RJ: Civilização Brasileira, 2011. p. 21-44.

DAMASCENO, V. O. et al. Imagem corporal e corpo ideal. Revista brasileira de Ciência e Movimento, Águas Claras, v. 14, n. 1, p. 8796, 2006. Disponível em: <http://portalrevistas.ucb.br/index.php/RBCM/article/view/691/696>. Acesso em: 17 out. 2011.

DANTAS, E. et al. Imagem Corporal, insatisfação e tipo físico ideal. In: DANTAS, E. H. M. (Org). Pensando o corpo e o movimento. Rio de Janeiro: Shape, 2005. p. 17-31.

FERNANDES, M. G. Problematizando o corpo e a sexualidade de mulheres idosas: o olhar de gênero e geração. Revista de Enfermagem, Rio de Janeiro, v. 17, n. 3, p. 418-22, jul/set, 2009. Disponível em: $<$ http://www.facenf.uerj.br/v17n3/v17n3a21.pdf $>$. Acesso em 22 mar. 2011.

FERREIRA, M. E. C.; BAUMEL, R. C. R.; GOMES, G. A busca frenética pelo corpo "ideal". In: ROMERO, E.; PEREIRA, E. G. B. (Org) $\mathbf{O}$ universo do corpo masculinidades e feminilidades. Rio de Janeiro: Shape, 2008. p. 305-330.

GOMES, E. S.; LIMA, M. F.; SILVA, P. N. Estudo e Pesquisa Monográfica. João Pessoa: UFPB, 2004.

INSTITUTO BRASILEIRO DE GEOGRAFIA E ESTATÍSTICA (IBGE). Síntese dos indicadores sociais: Uma analise das condições de vida da população brasileira. Estudos e pesquisas - informação demográfica e socioeconômica. $\mathrm{n}^{\circ} 27$. Rio de Janeiro, 2010. Disponível em: <http://www.ibge.gov.br/home/estatistica/populacao/condicaode- 
vida/indicadoresminimos/sinteseindicsociais2010/SIS_2010.pdf $>$. Acesso em 19 mar. 2011

IBIAS, C. I. Velhice e Vida, Uma Parceria a Ser Vivida. In: TERRA, N.L.; DORNELLES, B. (Orgs.) Envelhecimento bem sucedido. 2. ed. Porto Alegre: EDIPUCRS, 2003. p. 245-254

LE BRETON, D. A sociologia do Corpo. 2. ed. Tradução de Sônia M. S. Fuhrmann. Petrópolis, RJ: Vozes, 2007.

MATSUO, R. F. et al. Imagem Corporal de Idosas e Atividade Física. Revista Mackenzie de Educação Física e Esporte, São Paulo, v. 6, n. 1, p. 37-43, 2007. Disponível em: <http://www3.mackenzie.br/editora/index.php/remef/article/viewFile/1281/985>. Acesso em 07 set. 2011.

MAZO, G. Z.; LOPES, M. A.; BENEDETTI, T. B. Atividade Física e o Idoso: Concepção Gerontológica. 3. ed. Porto Alegre: Sulina, 2009.

MEDIONDO, M. S.; BULLA, L. C. Idoso, Vida Cotidiana e Participação Social. In: TERRA, N. L.; DORNELLES, B. (Orgs.) Envelhecimento bem sucedido. 2. ed. Porto Alegre: EDIPUCRS, 2003. p. $271-281$

MORAES, A. O corpo no tempo: velhos e o envelhecimento. In: DEL PRIORE, M.; AMANTINO, M. (Orgs.). História do corpo no Brasil. São Paulo: Editora UNESP, 2011. p. 427-452

MUCIDA, A. O sujeito não envelhece: psicanálise e velhice. 2. ed. Belo Horizonte: Autêntica, 2006.

NAHAS, M. V. Envelhecer com vigor. In: Atividade física, saúde e qualidade de vida: conceitos e sugestões para um estilo de vida ativo. 5. ed. Londrina: Midiograf, 2010. p 191- 205.

RAUCHBACH, R. A Atividade Física para $3^{0}$ Idade: Envelhecimento ativo, uma proposta para a vida. Londrina: Midiograf, 2001.

SANTAELlA, L. Corpo e Comunicação: Sintoma da cultura. 3. ed. São Paulo: Paulus, 2008. 
SHILDER, P. A imagem do corpo. Tradução de Rosanne Wetman. São Paulo: Martins Fontes, 1980.

SIBILA, P. Imagens de corpos velhos: a moral da pele lisa nos meios gráficos e audiovisuais. In: COUTO, E. S.; GOELLNER, S. V. (Orgs.) O triunfo do Corpo: polêmicas contemporâneas. Petrópolis, RJ: Vozes, 2012. p. 145-160

SOUZA, S.A. JÚNIOR, E.D. Procurando entender as questões de gênero num projeto voltado à população idosa. In: SILVA, K. N. P; SILVA, J. A. A. (Orgs.) Recreação, Esporte e Lazer: Espaço Tempo e Atitude. Recife: Instituto Tempo Livre, 2007. p. 403-408.

SIMÕES, R. Corporeidade e Terceira Idade: a marginalização do corpo idoso. 3. ed. Piracicaba: UNIMEP, 1998.

SIQUEIRA, F. V. et al. Atividade física em adultos e idosos residentes em áreas de abrangência de unidades básicas de saúde de municípios das regiões Sul e Nordeste do Brasil. Cadernos de Saúde Pública, Rio de Janeiro, v. 24, n. 1, p. 39-54, jan., 2008. Disponível em: $<$ http://www.scielosp.org/pdf/csp/v24n1/04.pdf $>$. Acesso em 30 maio 2011

TRIBESS, S.; VIRTUOSO-JUNIOR, J. S.; PETROSKI, E. L. Fatores Associados à Inatividade Física em Mulheres Idosas em Comunidades de Baixa Renda. Revista de Salud pública, Bogotá, v. 11, n. 1, p. 39-49, jan./feb., 2009 . Disponível em: <http://www.scielosp.org/scielo.php?script=sci arttext\&pid=S0124$00642009000100005 \& \operatorname{lng}=$ en\&nrm=iso $>$.

Acesso em 10 out. 2011.

VAZ, R. A.; NODIN, N. A importância do exercício físico nos anos maduros da sexualidade. Análise Psicológica, Lisboa, v. 23, n. 3, p.329-339, jul., 2005. Disponível em: <http://www.scielo.oces.mctes.pt/pdf/aps/v23n3/v23n3a11.pdf>.

Acesso em 20 mar. 2011

VERAS, R. Novos desafios para o jovem país envelhecido. In: GOLDENBERG, M. (Org). Corpo, envelhecimento e felicidade. RJ: Civilização Brasileira, 2011. p. 329-340 
VITOLA, J.; ARGIMON, I. L. Aspectos Psicológicos do Envelhecimento. In: TERRA, N.L.; DORNELLES, B.( Orgs.) Envelhecimento bem sucedido. 2. ed. Porto Alegre: EDIPUCRS, 2003. p. 97-101.

Recebido em: 16/11/2012

Revisado em: 07/01/2013

Aprovado em: 21/03/2013

\section{Endereço para correspondência}

iraqui@uol.com

Iraquitan de Oliveira Caminha

Universidade Federal da Paraíba,

Centro de Ciências da Saúde

Campus I, Departamento de Educação Física.

Capus I - Cidade Universitária

Castelo Branco

58059-900 - Joao Pessoa, PB - Brasil 